\title{
FATORES RISCO PARA O HIV/AIDS EM MULHERES CASADAS OU QUE VIVEM PARCERIA ESTÁVEL
}

\section{ARTIGO DE REVISÃO}

XAVIER, Luciana da Silva ${ }^{1}$

TAVARES, Luciana Venhofen Martinelli ${ }^{2}$

BARROS, Simone Regina Alves de Freitas ${ }^{3}$

XAVIER, Luciana da Silva. TAVARES, Luciana Venhofen Martinelli. BARROS, Simone Regina Alves de Freitas. Fatores risco para o HIV/AIDS em mulheres casadas ou que vivem parceria estável. Revista Científica Multidisciplinar Núcleo do Conhecimento. Ano 05, Ed. 02, Vol. 04, pp. 47-60. Fevereiro de 2020. ISSN: 24480959, Link de acesso: https://www.nucleodoconhecimento.com.br/saude/fatoresrisco-para-o-hiv-aids

\section{RESUMO}

O principal objetivo do estudo foi identificar na literatura fatores de risco para o HIV em mulheres casadas ou que vivem união estável. Para coleta dos dados foi realizada uma revisão integrativa sobre o tema, na revista eletrônica Scielo onde foram selecionados artigos em português publicado nos últimos dez anos. Foi constatado que diversos fatores podem influenciar na não adoção de medidas para esta população colocando-as em situação de vulnerabilidade, como por exemplo as crenças errôneas em relação ao uso do preservativo e ao HIV/Aids, à suposta proteção atrelada ao relacionamento estável, à fidelidade do companheiro e o medo de quebrar os laços de confiança e desestabilizar a relação. As discrepâncias de

\footnotetext{
${ }^{1}$ Enfermeira. Hospital Universitário Professor Alberto Antunes de Alagoas.

2 Docente. Portal da Educação.

${ }^{3}$ Enfermeira. Hospital Universitário Professor Alberto Antunes de Alagoas.
} 
gênero foram descritas como fatores importantes para o aumento de casos de HIV em mulheres em situação de conjugalidade. Foi concluído que os mitos e crenças naturalizados na cultura no que se refere aos comportamentos de gênero, atuam negativamente para a população estudada prevenir a doença de forma efetiva, havendo, portanto, a necessidade de preparo para profissionais de saúde possam discutir questões ligadas à sexualidade dessas mulheres e de se investir em estudos com objetivo de descobrir novas tecnologias para conscientizá-las quanto à susceptibilidade que estão expostas e trabalhar o emponderamento intrapessoal, incentivar autonomia e resiliência para se tornem ativas em relação à sua saúde e consequentemente possam desenvolver mecanismos de proteção ao HIV/Aids.

Palavras-chave: HIV, gênero feminino, cultura, amor, prevenção.

\section{INTRODUÇÃO}

A ocorrência de casos de HIV em mulheres foi detectada desde seu surgimento na década de 80 , entretanto os casos eram restritos a mulheres parceiras de usuários de drogas injetáveis, de hemofílicos, de homens bissexuais ou prostitutas. Em 2006 $32,8 \%$ dos casos notificados foram do sexo feminino. A razão entre os sexos vem diminuindo sistematicamente (BRASIL, 2007).

A relação heterossexual e a forma que mais tem contribuído para a feminização da epidemia. Pesquisas mostram que ao longo dos anos vem ocorrendo, no Brasil uma diminuição significativa da relação homem: mulher. Em 1983 ela era de 40 homens para uma mulher e em 2007 diminuiu para 1,4 homens para uma mulher. (SILVA et. al, 2010).

Segundo Taquette (2010), a epidemia avança cada vez mais entre mulheres heterossexuais, monogâmicas, que não pertencem a nenhum grupo de risco e nem têm comportamentos sexuais de risco, ao contrário, estas mulheres se enquadram no perfil conservador e tradicional, no que diz respeito ás práticas sexuais, ou seja, representam o oposto do considerado desviante dos principais acometidos no início da descoberta da epidemia. 
Existem poucos relatos de estudos relacionados ao HIV e mulheres que vivem união estável, porém há evidencias de que o aumento da proporção de mulheres infectadas por parceiros fixos, sugere a baixa percepção do risco delas se contaminarem, a impossibilidade de negociar o sexo seguro com o parceiro ou até mesmo a dificuldade de sair da relação de risco (SANTOS, 2009).

Para Garcia e Sousa (2010), os constantes aumentos de casos de aids entre mulheres com parcerias estáveis ocorrem devido aos aspectos econômicos e socioculturais o que colocam este grupo em situação de vulnerabilidade crescente.

Atualmente há poucas discussões acerca do uso do preservativo entre casais na literatura, entretanto fica evidente em diversos estudos que os valores culturais sobre amor e felicidade se tornam impeditivos para adoção de medidas preventivas tornando estas pessoas mais susceptíveis a infecção do HIV (MAIA, GUILHERME; FREITAS, 2008).

A presente pesquisa justifica-se pelo fato de estudiosos apresentarem achados na literatura brasileira da existência de elevado risco para infecção por HIV nesses tipos de relacionamentos, uma vez que muitas mulheres sentem-se protegidas, considerando o HIV um agravo distante de sua realidade, além do fato de haver uma resistência para usar o preservativo devido às questões culturais e a dificuldade de negociar o seu uso com o parceiro por diversos fatores que as levam a se submeterem a decisão do parceiro de não usar.

Diante disto o objetivo da pesquisa é identificar na literatura fatores de risco para infecção do HIV em mulheres casadas ou que vivem união estável, assim como também, descrever fatores culturais e afetivos que contribuem para a infecção e identificar fatores sociais correlacionados a não adoção de medidas preventivas nesta população. 


\section{METODOLOGIA}

Foi realizada uma revisão integrativa a partir de fontes secundárias cuja finalidade desse tipo pesquisa é reunir informações sobre um determinado tema para auxiliar na busca de respostas ou resolução de problemas de saúde na sociedade, como afirma:

Diante da necessidade de assegurar uma prática assistencial embasada em evidências científicas, a revisão integrativa tem sido apontada como uma ferramenta ímpar no campo da saúde, pois sintetiza as pesquisas disponíveis sobre determinada temática e direciona a prática fundamentando-se em conhecimento científico (SOUSA; SILVA; CARVALHO, p. 105, 2010).

Para levantamento dos dados foi realizada uma busca na revista eletrônica Scientific Electronic Library Online (Scielo), utilizando os seguintes descritores: HIV: Gênero Feminino; Cultura; Amor; Prevenção. Os critérios usados para seleção dos artigos foram: artigos publicados em português nos últimos 10 anos, período compreendido entre 2006 e 2016, relacionados ao tema proposto.

\section{RESULTADOS E DISCUSSÃO}

Observamos em nossa busca que não existem muitos artigos na literatura portuguesa que tratem especificamente sobre a relação de mulheres casadas e HIV/Aids. Para obter os resultados da pesquisa foi constituída uma amostra de 15 artigos científicos encontrados na revista Scientific Electronic Library Online (Scielo). Na tabela 1, estão representados o título, autor e ano da pesquisa. Na tabela 2, descrevem-se os objetivos de cada estudo.

De acordo com os autores do estudo 1, pesquisa realizada em São Paulo e recife constatou-se que muitas mulheres se colocam em risco de contrair o HIV por que se sentem protegidas pelo relacionamento estável. Uma vez que acreditam que seus parceiros não usam preservativo em casa, mas usam com supostas parceiras eventuais, entretanto, nem sempre eles o fazem, pois alguns também consideram 
relacionamentos extraconjugais estáveis (GARCIA; SOUSA, 2010). Além disso, para muitos casais existe uma ideia de prevenção atrelada ao parceiro que é conhecido e não vai expor o outro ao risco de contrair DSTs (OLTRAMARI e CAMARGO, 2010; RODRIGUES e PRAÇA, 2010).

Acredita-se que muitas mulheres não estão conscientes do risco de contrair o HIV, pois muitas vezes estão se sujeitando a suposta proteção do seu parceiro fora de casa. Segundo Praça e Rodrigues (2010), conforme estudo 13, a crença na fidelidade do companheiro e não valorização do seu passado, no que diz respeito a comportamentos que poderia tê-lo infectado são fatores que geram o não emprego do preservativo nessas relações.

Tabela 1 - Estudos pesquisados, autores e ano da pesquisa

\begin{tabular}{|c|c|c|c|}
\hline ESTUDO & TíTULO & AUTORES & ANO \\
\hline 1 & $\begin{array}{l}\text { Vulnerabilidades ao HIV/aids no Contexto } \\
\text { Brasileiro: } \\
\text { Iniquidades de gênero, raça e geração. }\end{array}$ & GARCIA e SOUSA & 2010 \\
\hline 2 & $\begin{array}{l}\text { Associação entre violência por parceiro } \\
\text { íntimo contra } \\
\text { A mulher e infecção por HIV. }\end{array}$ & $\begin{array}{l}\text { BARROS; } \\
\text { SCHRAIBER; } \\
\text { FANÇA-JUNIOR. }\end{array}$ & 2010 \\
\hline 3 & $\begin{array}{l}\text { Vulnerabilidade ao HIV/Aids de pessoas } \\
\text { heterossexuais casadas ou em união } \\
\text { estável. }\end{array}$ & $\begin{array}{l}\text { MAIA; } \\
\text { GUILHERME e } \\
\text { FREITAS }\end{array}$ & 2008 \\
\hline 4 & $\begin{array}{l}\text { Vulnerabilidade de mulheres em união } \\
\text { heterossexual } \\
\text { estável à infecção pelo HIV/Aids: estudo } \\
\text { de } \\
\text { representações sociais. }\end{array}$ & $\begin{array}{l}\text { RODRIGUES et. } \\
\text { al. }\end{array}$ & 2012 \\
\hline
\end{tabular}


Contextos de vulnerabilidade para o HIV SANTOS et.al.

2009 entre

mulheres brasileiras.

6

\begin{tabular}{lll|l|l}
$\begin{array}{l}\text { Percepção de mulheres quanto a } \\
\text { vulnerabilidade }\end{array}$ & $\begin{array}{l}\text { SILVA } \\
\text { VARGENS }\end{array}$ & e 2009
\end{tabular}

feminina para contrair DST/Aids.

7

Interseccionalidade de gênero, classe e TAQUETTE raça e

vulnerabilidade de adolescentes negras às DST/AIDS.

8

Diferenças entre Adolescentes o Sexo ANJOS et.al.

2012

Feminino e

Masculino na Vulnerabilidade Individual ao HIV.

9 Infecções Genitais em Mulheres BARCELOS et.al. 2008 Atendidas em Unidade

Básica de Saúde: Prevalência e Fatores de Risco.

10 Aids, Relações Conjugais e Confiança: OLTRAMARI E 2010 Um Estudo

\section{CAMARGO}

sobre Representações Sociais.

11 Presentes perigosos: dinâmicas de risco MANUEL de infecção ao

HIV/AIDS nos relacionamentos de namoro em Maputo. 


\begin{tabular}{|c|c|c|c|}
\hline 12 & $\begin{array}{l}\text { Construindo Caminhos de } \\
\text { Conhecimentos em } \\
\text { HIV/Aids: mulheres em cena. }\end{array}$ & SILVA e REIS & 2012 \\
\hline 13 & $\begin{array}{l}\text { Mulheres com Idade Igual ou Superior a } \\
50 \text { Anos: ações preventivas da infecção } \\
\text { pelo HIV. }\end{array}$ & $\begin{array}{l}\text { RODRIGUES e } \\
\text { PRAÇA }\end{array}$ & 2010 \\
\hline 14 & $\begin{array}{l}\text { Gênero, Vulnerabilidade das Mulheres ao } \\
\text { HIV/ Aids e } \\
\text { Ações de Prevenção em Bairro da } \\
\text { Periferia de } \\
\text { Teresina, Piauí, Brasil. }\end{array}$ & $\begin{array}{l}\text { SOUSA; SANTO e } \\
\text { MOTA. }\end{array}$ & 2008 \\
\hline 15 & $\begin{array}{l}\text { Mulheres e o HIV/AIDS: Intersecções } \\
\text { Entre } \\
\text { Gênero, Feminismo Psicologia e Saúde } \\
\text { Pública. }\end{array}$ & $\begin{array}{l}\text { MUHLEN; } \\
\text { SALDANHA } \\
\text { E STREY. }\end{array}$ & 2014 \\
\hline
\end{tabular}

Fonte: Dados da pesquisa.

Conforme o estudo 3 de Maia e colaboradores (2008), investigação feita com pessoas heterossexuais casadas ou em união consensual, também se observou o uso do preservativo restrito, tanto nas relações conjugais como nas extras conjugais. Para o pesquisador o uso do preservativo esteve por muito tempo ligado à prostituição, promiscuidade e relações extraconjugais. Talvez isso explique um dos motivos pelos quais existe resistência por parte do ser masculino em aderir esse tipo de prevenção em relações consideradas estáveis.

Essa visão de leviandade ligada ao uso do preservativo masculino dificulta a aceitação do seu uso dentro de casa. Pois para alguns homens, a exigência do uso do preservativo por parte da parceira fixa, pode gerar a desconfiança de que eles estão 
sendo traídos e precisam se proteger delas, aceitando seu uso somente como método contraceptivo (GARCIA; SOUSA, 2010).

Foi constatado no estudo 6, por Silva e Vargens (2009), que a percepção das mulheres para contrair DST/Aids, em muitas entrevistadas, revelou que se sentem inibidas de exigir a camisinha do seu parceiro temendo ser mal interpretada, porque seus companheiros acham que se elas exigem o preservativo é porque existe promiscuidade.

Vários estudos comprovam e eficácia do uso do preservativo em relacionamentos estáveis. No estudo 8, a fidelidade a um único parceiro também se mostra bemsucedida na prevenção de HIV/aids em relações heterossexuais (ANJOS et. al., 2008).

O estudo 7 de Taquette (2010), constatou que em muitos casos, as meninas abandonam o uso do preservativo ainda quando estão namorando, prevalecendo a confiança nos seus parceiros, mesmo afirmando que todos os homens são infiéis. Conforme citado no estudo 10, um dos fatores que mais dificultaram o uso do preservativo entre mulheres adolescentes, foi a imprevisibilidade do relacionamento, quanto mais a relação sexual foi inesperada mais precárias foram as condições de prevenção. Para as entrevistadas a prevenção comprometia a idoneidade delas perante os pais (OLTRAMARI e CAMARGO, 2010).

No entanto, Manuel (2009) -estudo 11 -verificou através de relatos de casais de namorados (relacionamentos fixos), que a dificuldade de usar preservativo entre esses casais está ligada ao significado de 'sexo verdadeiro'. Para eles esse tipo de sexo é exclusivamente sexo vaginal sem nenhum tipo de barreira, pois assim podese desfrutar do contato íntimo e sentir o calor do sangue do parceiro, criando laços fortes e sensação de unidade, proporcionando a confiança de que o relacionamento é baseado no amor. Não obstante, esses jovens trocam de parcerias estáveis frequentemente gerando a chamada monogamia serial, já que é estabelecida uma relação estável e sexo verdadeiro' a cada novo parceiro, dessa maneira, reduzindo a proteção contra o HIV/Aids. 
Tabela 2 - Objetivo dos estudos pesquisados

\begin{tabular}{|c|c|}
\hline Estudo & Objetivo \\
\hline 1 & $\begin{array}{l}\text { Analisar o conhecimento da população sobre DST/AIDS,bem como os } \\
\text { discursos sobre o uso do preservativo e das práticas sexuais. }\end{array}$ \\
\hline 2 & $\begin{array}{l}\text { Analisar a associação entre a violência por parceiro íntimo contra mulheres } \\
\text { e a infecção ou suspeita de infecção pelo vírus da imunodeficiência humana } \\
\text { (HIV). }\end{array}$ \\
\hline 3 & $\begin{array}{l}\text { Estudar conhecimentos, comportamentos preventivos e percepções em } \\
\text { relação ao HIV/Aids de homens e mulheres heterossexuais casados ou em } \\
\text { união consensual. }\end{array}$ \\
\hline 4 & $\begin{array}{l}\text { Discutir as representações Sociais de mulheres em união heterossexual } \\
\text { estável no que diz respeito à vulnerabilidade à infecção pelo HIV/AIDS. }\end{array}$ \\
\hline 5 & $\begin{array}{l}\text { Identificar os contextos de vulnerabilidade para o HIV entre mulheres } \\
\text { brasileiras. }\end{array}$ \\
\hline 6 & $\begin{array}{l}\text { Analisar a percepção de mulheres quanto à vulnerabilidade feminina para } \\
\text { contrair DST/HIV. }\end{array}$ \\
\hline 7 & $\begin{array}{l}\text { Verificar a vulnerabilidade ao HIV/aids de adolescentes femininas moradoras } \\
\text { de favelas da cidade do Rio de Janeiro. }\end{array}$ \\
\hline 8 & $\begin{array}{l}\text { Analisar comparativamente vulnerabilidade ao HIV/ AIDS de homens e } \\
\text { mulheres adolescentes, baseada em seus conhecimentos, valores e } \\
\text { práticas. }\end{array}$ \\
\hline 9 & $\begin{array}{l}\text { Descrever a prevalência e o perfil comportamental para infecções genitais } \\
\text { em mulheres atendidas em uma Unidade Básica de Saúde em Vitória, } \\
\text { Espírito Santo. }\end{array}$ \\
\hline 10 & $\begin{array}{l}\text { Compreender a influência das representações sociais da Aids na prevenção } \\
\text { dos comportamentos de vulnerabilidade ao HIV, nas relações de } \\
\text { conjugalidade entre homens e mulheres heterossexuais. }\end{array}$ \\
\hline 11 & $\begin{array}{l}\text { Explorar as percepções e práticas sexuais entre jovens no Moçambique pós- } \\
\text { colonial e pós-socialista, especificamente na cidade de Maputo. }\end{array}$ \\
\hline
\end{tabular}


Identificar o acesso à informação das mulheres sobre o HIV/Aids e analisar os fatores que as orientam na adoção de medidas protetoras ao HIV/Aids.

13 Verificar a adoção de ações preventivas da transmissão do HIV por mulheres com idade igual ou superior a 50 anos.

14 Identificar a vulnerabilidade desse grupo à infecção pelo HIV, em função da utilização ou não de preservativo, bem como a relação desse aspecto com as relações de gênero vivenciadas pelos parceiros e o papel do Programa Saúde da Família nesse contexto.

15 Visibilizar as tramas das relações desiguais de poder entre mulheres e homens e os efeitos na saúde sexual das mulheres.

Fonte: Dados da pesquisa.

Julga-se que essas informações são fundamentais para que possamos atentar para realização de educação em saúde para jovens e adolescentes do sexo feminino, com o objetivo de motivar o uso da camisinha desde cedo. Levando-se em consideração que este grupo se encontrar em situação de vulnerabilidade para contrair DSTs/HIV, por estarem vivenciando uma fase de descobertas, principalmente em relação à sexualidade, mas ao mesmo tempo estão em momento oportuno para receber orientações, que muitas vezes, são consideradas tabu dentro de casa.

rcebe-se diante do contexto, a necessidade de encontrar maneiras para que estas mulheres possam dialogar com seus parceiros e por outro lado transformar a visão preconceituosa em relação camisinha, que por sua vez está fortemente vinculada às crenças sexuais errôneas, que são inconscientemente introduzidas na cultura, em atitudes e ações conscientes em que pese mais o amor e o cuidado para preservação da saúde própria e do cônjuge. Pois se entende que não basta apenas garantir acesso à informação para mulheres enfrentar o problema, há também a necessidade ações que visem educar a população masculina para proteger a si e sua parceira.

Conforme o estudo 6 e 14 é essencial a elaboração de estratégias preventivas para envolver os homens no processo de mudança do quadro, já que os comportamentos 
masculinos atingem diretamente as mulheres (SILVA e VARGENS, 2009; SOUSA, SANTO e MOTA, 2008).

Evidencia-se no estudo 9 que a alta taxa de não uso de preservativos entre mulheres em relações conjugais, mostra a necessidade de campanhas sobre comportamentos sexuais e uso de camisinha para mulheres em relacionamentos estáveis (BARCELOS et. al., 2008).

Por outro lado, as percepções conjugais em relação à visão romântica do amor, fidelidade e confiança, os papeis de gênero e hierarquização do poder afetivo sexual, expressos na cultura, são considerados outros empecilhos importantes para não adoção de comportamentos preventivos efetivos entre casais (MAIA; GUILHERME; FREITAS, 2008). Esses dados corroboram com os achados encontrados no estudo 6 , o qual revela que as próprias mulheres reconhecem a ingenuidade feminina, a submissão das mulheres, a dependência afetiva, a carência e o romantismo como fatores de vulnerabilidade. Contraditoriamente muitas dessas mulheres acreditam estarem protegidas do HIV por relacionamento estável apontando outras mulheres com comportamentos liberais, que têm mais parceiros como mais susceptíveis em contrair a doença (SILVA e VARGENS, 2009).

Esse mesmo sentimento de segurança e percepção diminuída do risco para HIV foi relatado nos discursos de mulheres, as quais acreditam que o relacionamento monogâmico as protege da infecção (SOUSA, SANTO e MOTA, 2008; RODRIGUES e PRAÇA, 2010). Dado que, acreditam que seus companheiros são saudáveis e não se arriscariam a se infectarem com outras mulheres desconhecidas por sentir medo da doença (RODRIGUES e PRAÇA, 2010).

Rodrigues e colaboradores (2012), no estudo 4, constaram em um grupo de mulheres da capital de Salvador, com união estável entre 6 e 10 anos e menor nível de escolaridade, têm percepções semelhantes. Estas mulheres julgaram-se distantes da infecção por HIV, visto que relataram que mulheres que têm ou podem ter HIV/Aids são irresponsáveis e têm comportamentos promíscuos, crenças conservadoras, que para o pesquisador, podem ser explicadas pelo fato desse grupo com maior tempo de 
relacionamento estável reproduzir o conhecimento decorrente de informações veiculadas por campanhas publicitárias de prevenção de forma normativa.

Já as mulheres com menor tempo de vida conjugal em comum, procedentes do interior, demonstraram medo da infecção pelo vírus, entretanto apresentaram passividade no que diz respeito a sua proteção individual, conferindo maior importância ao papel social de esposa e satisfação das necessidades sexuais do marido, por outro lado sentem-se inseguras, uma vez que não detém mecanismos eficientes para sua prevenção efetiva (RODRIGUES et. al. 2012).

Opiniões concordantes também foram destacadas no estudo 10, através de entrevistas com casais que vivem em situação de conjugalidade, mulheres demostraram ter controle e proteção imaginária sobre a Aids, por acreditarem que a doença ainda acomete apenas pessoas com comportamentos desviantes ou perigosos (OLTRAMARI e CAMARGO, 2010). Em conformidade, Silva e Reis (2012), relatam que este sentimento da suposta segurança ligado a conjugalidade faz com que mulheres não se sintam vulneráveis ao HIV.

Diante do exposto, é possível observar que as estratégias voltadas para a população em geral, não estão sendo efetivas para conscientizar esse grupo de mulheres, carecendo, portanto, de medidas mais amplas para o atual contexto, com o objetivo de diminuir o preconceito e conscientizar comportamentos mais saudáveis para o exercício da sexualidade dessas mulheres. Observa-se também a carência desvincular a proteção ao HIV da estabilidade do relacionamento e trabalhar o diálogo entre casais para aumentar o poder de decisão da mulher em relação à proteção sexual, pois o atualmente o homem, em muitos casos, é quem se torna o responsável pela saúde sexual da mulher.

Segundo Sousa e colaboradores no estudo 14, para algumas mulheres é difícil dialogar com seu parceiro sobre prevenção dentro de casa, algumas usam o argumento de que não está usando anticoncepcional para poder convencer o companheiro, outras acabam aceitando não usar como crédito de confiança, ficando o parceiro intimado a honrá-lo sob ameaça de retaliações. Em outros casos, a 
camisinha é usada de forma alternada, dependendo de suspeitas temporárias em relação ao comportamento sexual do companheiro.

Para mudar essa realidade, conforme dados do estudo 15, existe a necessidade de trabalhar o emponderamento intrapessoal das mulheres envolvidas. Emponderar é o ato do indivíduo se apossar de recursos internos como autonomia, emancipação, habilidade para expressar sentimentos, participar de problemas da sociedade, ou seja, tornar os sujeitos ativos nos processos da vida, como por exemplo, no exercício da conjugalidade igualitária, na busca por um lugar no mercado de trabalho, no tratamento ou na prevenção de doenças, na denúncia de maus tratos ou gestão de sua sexualidade (MUHLEN; SALDANHA e STREY, 2014).

Denota-se no estudo 12 que para trabalhar aspectos educacionais de prevenção no que se refere ao aprendizado para mudanças de comportamentos, há requerimento esforços coletivos voltados para atender as diversidades culturais. Para que isso ocorra de forma efetiva, é preciso investir na formação dos profissionais de saúde, assim como docentes para qualificação em educação sexual para compreender as vulnerabilidades para HIV/AIDS (SILVA e REIS, 2012).

Acredita-se na precisão de uma proposta que englobe multidisciplinaridade e interdisciplinaridade para que ocorra de fato trabalho em equipe com a finalidade de encontrar caminhos para diminuir os impactos negativos das diferenças de gênero e a susceptibilidade feminina para HIV/Aids. Isto pode ser possível através da incorporação dos diversos profissionais ligados a assistência da mulher, que muitas vezes deixam passar despercebidas situações ligadas à sexualidade que as colocam em risco para doença, como por exemplo, enfermagem, psicologia, assistência social.

A susceptibilidade ao HIV das mulheres em questão, bem como atitudes e comportamentos passivos da população estudada são reflexos das desigualdades de gênero e de renda, que contribuem para a não adoção de medidas preventivas entre mulheres. As variáveis vinculadas as desigualdades de gênero, como a inexistência de políticas públicas que efetivem os direitos humanos das mulheres, é preciso não enfoque apenas o direito reprodutivo em relação à mulher, como também a falta de 
acesso aos direitos sexuais de meninas e mulheres, falta de acesso à educação, persistência de padrões culturais e religiosos impeditivos de adoção de medidas preventivas, condições precárias de trabalho e violência doméstica. Situações que se expressam desfavorável às mulheres gerando diversas formas de discriminação quanto ao exercício da sexualidade (BRASIL, 2007).

De acordo com estudo 6, gênero e a forma de apontar construções sociais de modo a idealizar papeis diferentes para homens e mulheres. Relações conjugais menos assimétricas constituem fator decisivo para diminuição para vulnerabilidade da população feminina para DST/AIDS, apontando para a importância para do profissional de saúde investir no emponderamento dessas mulheres como caminho para regredir as desigualdades existentes (SILVA e VAGENS, 2009).

Segundo Taquette (2010), os comportamentos de gênero são aprendidos desde cedo dentro de casa. Observou-se em depoimentos, que a menina quando deixa de ser virgem, começa a ser vista de forma diferente pelos próprios familiares, por envergonha-los.

Diante das circunstâncias, percebe-se que as desigualdades de gênero constituem numa questão muito mais complexa, não estando atrelada apenas as atitudes masculinas, mas sim reflexo da visão da sociedade como um todo, necessitando de políticas e esforços para desnaturalizar a subordinação da mulher em relação ao seu parceiro.

Ressalta-se no estudo 8, que estas representações de gênero são passíveis de mudanças, pois muitos padrões estabelecidos são prejudiciais para o modo de viver das pessoas, trata-los como naturais, sem pensar nas consequências desses padrões de masculinidade e feminidade pode causar impactos à saúde, pois ambos se tornam vulneráveis às DSTs/HIV. A mulher torna-se mais susceptível devido à falta de poder de negociação e controle sobre a relação. Já para o homem aumenta devido à pressão social de exercer sua masculinidade estando sempre pronto para o sexo sem controle sobre seus impulsos (ANJOS, 2012). 
Sousa e colaboradores (2008), afirmam ser preciso levar em consideração que a prevenção ao HIV não depende apenas dos conhecimentos e atitudes de homens e mulheres, mas da forma que vivenciam o gênero. Os condicionantes que influenciam na decisão destas pessoas não usar preservativo exige um trabalho que vá além dos instrumentos tradicionais, ou seja, é preciso fortalecer os laços de confiança entre mulher e profissional para que haja um diálogo aberto sobre sexualidade, em que possam ser expressados sentimentos, angústias, medos e desejos, o que representará um avanço na busca da integralidade.

Numa pesquisa comparativa realizada com mulheres com diagnóstico de HIV/AIDS e mulheres soro negativas em 13 municípios brasileiros (estudo 5) foi destacado que casos de início da vida sexual precoce, uso de drogas, a baixa adesão do uso do preservativo, teve a maior proporção de casos de DST, a violência sexual entre mulheres vivendo com AIDS foram significativamente maiores em ralação ao outro grupo pesquisado (SANTOS et. al., 2009).

Estes dados chamam atenção para ampliação de um olhar mais cuidadoso para mulheres que se enquadram nesse perfil, uma vez que não são raros os casos encontrados em nosso território brasileiro de mulheres que sofrem violência doméstica e não têm poder de decisão sobre si mesma, de mulheres que casam e engravidam cada vez mais cedo em comunidades carentes, mulheres que frequentam as unidades de saúde constantemente para tratar DSTs.

É importante destacar também, a importância de levar informações para diminuir a descriminação a doença, visto que nestes casos é imprescindível a realização de testes sorológicos de rotina para diagnóstico precoce, quando não for mais possível a prevenção da infecção por HIV, evitando assim maiores repercussões negativa para vida dessas mulheres. Segundo o estudo5, já citado anteriormente, mais da metade das mulheres infectadas conheceu seu status sorológico quando foi diagnosticada a doença no seu companheiro, nela própria ou em um filho. Muitas delas contraíram o vírus de parceiro único (SANTOS et. al, 2009). 
Ainda existe muita resistência também por parte das mulheres para realização do teste anti-HIV, justificando-se apenas para sanar dúvidas perante relacionamentos arriscados (OLTRAMARI e CAMARGO, 2010). Atualmente no atendimento individual ás mulheres parece prevalecer ainda, a noção de comportamento de risco, ficando as mulheres casadas dispensadas de orientações e oferta do teste (SOUSA, SANTO e MOTA, 2008).

Para Barros e colaboradores (2010), no estudo 2, casos de infecção por HIV podem estar associados à violência por parceiro intimo contra a mulher. Ainda de acordo com o autor, há uma necessidade urgente de se voltar o olhar para mulheres que sofrem violência sexual por seus parceiros íntimos, uma vez que na maioria das vezes a atenção do profissional de saúde está direcionada apenas para mulheres que sofrem violência praticada por estranhos. Para ele, a violência marital sofrida por mulheres deve ser também monitorada no momento da procura por serviços de saúde, com oferta de testes anti-HIV e aconselhamento.

A infecção por HIV pode ser fruto de relações sexuais conturbadas, efeito negativo das discrepâncias de poder e vulnerabilidade da mulher que consiste num problema de saúde pública. Segundo o estudo a violência doméstica é muitas vezes banalizada, aceita como normal pela sociedade, fato que dificulta o reconhecimento de situações limites (MUHLEN; SALDANHA e STREY, 2014).

Conforme o estudo 15, a psicologia feminista tem papel fundamental no questionamento dos modelos hegemônicos de gênero. Para o autor, essa terapia é de grande valia para as mulheres vulnerabilidades por atuar numa lógica de intervenção individual, social e comunitária, cujo objetivo é reabilitar o ideal de igualdade entre os sexos e promover o emponderamento (resiliência e autonomia) das mulheres vítimas de violência em todo seu espectro (MUHLEN; SALDANHA e STREY, 2014).

Atualmente o tema violência doméstica vem sendo muito discutida na mídia, pois é cada vez mais crescente o número de casos descobertos, merecendo, de pesquisas e esforços dos gestores e profissionais da saúde para combater esse tipo de agravo. 
Acredita-se que para se obter resultados satisfatórios seja preciso ofertar atenção de forma integral para o grupo afetado, como por exemplo, envolver questões que atendam a saúde da mulher como um todo e facilitem o acesso aos serviços e a educação em saúde, criação de grupos de apoio, promoção da saúde mental, elevação da autoestima, bem como ações intersetoriais para aumentar oferta emprego e diminuir as desigualdades de renda e de gênero, questões que são tidas como coadjuvantes para relações maritais consideradas de risco para HIV/Aids.

Há necessidade de articular ações intersetoriais, não apenas para aumentar a compreensão da vulnerabilidade ao HIV entre mulheres casadas, mas principalmente com o objetivo de favorecer condições econômicas, sociais e políticas para diminuir as desigualdades de poder dessas mulheres (RODRIGUES et. al., 2012). Dado que as mulheres são historicamente vítimas das disparidades existentes, sejam elas sociais, econômicas, físicas, culturais e sexuais (SILVA e REIS, 2012).

\section{CONSIDERAÇÕES FINAIS}

No decorrer da busca por resposta para questões levantadas na atual pesquisa pôdese constatar que existem mitos que habitam no imaginário das mulheres que vivem situação de conjugalidade, no que diz respeito à prevenção do HIV, que as impedem de perceber tal vulnerabilidade. Uma destas crenças está vinculada a suposta proteção do relacionamento estável. Muitas acreditam estarem protegidas, não por confiar na fidelidade do companheiro, pois admitem que podem ser traídas, mas por crer na conscientização do marido para usar o preservativo em relacionamentos extraconjugais, protegendo ambos da doença. Entretanto os estudos mostram quem nem sempre isto acontece, porque eles muitas vezes também não usam preservativo fora de casa, colocando-as em risco.

Além disso, ainda existe a ideia errônea de HIV atrelada a mulheres com comportamentos promíscuos e desviantes que faz com que muitas neguem a possibilidade de se infectarem por seu parceiro íntimo. Dado que, não duvidam da higidez do seu companheiro e acreditam que ele não ousaria fazer sexo sem preservativo com outra mulher, por temer a infecção por HIV. 
Somado a isso, ainda há quem reconheça que o preservativo está ligado à prostituição e promiscuidade, excluindo o seu uso para pessoas monogâmicas e conservadoras, como no caso de pessoas com vida conjugal. Sendo o seu uso inadmissível para casais que vivem relações de confiança, pois esse tipo de prevenção abalaria o amor e o romantismo ou até mesmo custaria o fim do relacionamento, a menos que o preservativo seja o usado para anticoncepção. As questões culturais e diferenças de gênero foram muito discorridas em todas as literaturas pesquisadas, sendo descritas como fatores importantes para vulnerabilidade da população estudada para HIV/aids, destacando-se a necessidade de se encontrar estratégias e novas tecnologias para conscientização dos efeitos negativos das discriminações de gênero para a saúde da mulher, especialmente parara infecção do HIV.

Observou-se a carência de preparo para profissionais de saúde discutir com a população estudada questões de gênero, saúde sexual da mulher e violência por parceiro íntimo, com o fim de diminuir o índice da infecção em mulheres casadas ou em parceria estável, uma vez que estudos comprovam que estes temas não são valorizados durante a procura dessas mulheres por serviços de saúde. Percebe-se a necessidade de trabalhar o emponderamento intrapessoal destas mulheres, ou seja, buscar artifícios e meios para conscientizar, dar autonomia, resiliência para que elas se tornem ativas no processo de cuidar da saúde e de prevenção da doença.

Sugere-se a realização de mais estudos específicos que proponham tecnologias e estratégias com a finalidade de diminuir a vulnerabilidade de mulheres em união estável para o HIV, uma vez que se constitui num tema complexo por envolver questões de gênero, afetividade e comportamento sexual.

\section{REFERÊNCIAS}

ANJOS, Renata Holanda Dutra dos et. al.. Diferenças entre Adolescentes o Sexo Feminino e Masculino na Vulnerabilidade Individual ao HIV. Rev Esc Enferm USP, 2012. Disponível em: http://www.scielo.br/pdf/reeusp/v46n4/07.pdf. Acesso em 18 jul de 2016. 
BARCELOS, Maria Rejane Barroso et. al. . Infecções Genitais em Mulheres Atendidas em Unidade Básica de Saúde: Prevalência e Fatores de Risco. Rev Bras Ginecol Obstet. 2008. Disponível em: http://www.scielo.br/pdf/rbgo/v30n7/a05v30n7.pdf. Acesso em 20 jul de 2016.

BARROS, Claudia; SCHRAIBE, Lilia Blimar; e FRANÇA-JUNIOR, Ivan. Associação entre Violência por Parceiro Íntimo contra a Mulher e infecção por HIV. Rev. Bras de Saúde Pública, 2010. Disponível em: http://www.scielo.br/pdf/rsp/v45n2/1924.pdf. Acesso em 15 jul de 2016.

BRASIL, Ministério da Saúde. Plano Integrado de Enfrentamento da Feminização da Epidemia de Aids e outras DST. 2007. Disponível em: http://bvsms.saude.gov.br/bvs/publicacoes/plano_feminizacao_final.pdf. Acesso em 12 agost de 2016.

GARCIA, Sandra e SOUSA, Fabiana Mendes. Vulnerabilidades ao HIV/aids no Contexto Brasileiro: iniquidades de gênero, raça e geração. Saúde e Sociedade. São Paulo, v.19, supl.2, p.9-20, 2010. Disponível em: http://www.scielo.br/pdf/sausoc/v19s2/03.pdf. Acesso em 02 abr. 2016.

MAIA, Christiane; GUILHEME, Dirce e FREITAS, Daniel. Vulnerabilidade ao HIV/Aids de pessoas heterossexuais casadas ou em união estável. Rev. Saúde Pública 2008;42(2):242-8. Disponível em: http://www.scielosp.org/pdf/rsp/v42n2/6357. Acesso em. 08 out. 20014

MANUEL, Sandra. Presentes perigosos: dinâmicas de risco de infecção ao HIV/Aids nos relacionamentos de namoro em Maputo. Physis Revista de Saúde Coletiva, Rio de Janeiro, 19 [ 2 ]: 371-386, 2009. Disponível em: http://www.scielo.br/pdf/physis/v19n2/v19n2a07.pdf. Acesso em 18 de agosto de 2016.

MUHLEN, Bruna Krimberg Von; SALDANHA, Marília e STREY, Marlene Neves. Mulheres e o hiv/aids: Intersecções Entre Gênero, Feminismo, Psicologia e Saúde Pública. Revista colombiana de psicologia, vol. 23 n. 을, julio-diciembre, 2014 p. 
285-296. Disponível em: http://www.scielo.org.co/pdf/rcps/v23n2/v23n2a04.pdf. Acesso em 20 agost 2016.

OLTRAMARI Leandro Castro CAMARGO, Brígido Vizeu. Aids, Relações Conjugais e Confiança: Um Estudo sobre Representações Sociais.

Psicologia em Estudo, Maringá, v. 15, n. 2, p. 275-283, abr./jun. 2010. Disponível em: http://www.scielo.br/pdf/pe/v15n2/a06v15n2.pdf. Acesso em 11 agost 2016.

RODRIGUES, Daniela Angelo de Lima e PRAÇA, Neide de Souza. Mulheres com Idade Igual ou Superior a 50 Anos: ações preventivas da infecção pelo HIV. Rev Gaúcha Enferm., Porto Alegre (RS) 2010 jun;31(2):32. Disponível em: http://www.scielo.br/pdf/rgenf/v31n2/17.pdf. Acesso em 24 agost de 2016.

RODRIGUES, Larissa Silva Abreu et. al. Vulnerabilidade de mulheres em união heterossexual estável à infecção pelo HIV/Aids: estudo de representações sociais. Rev Esc Enferm, USP, 2012; 46(2):349-55. Disponível em: http://www.scielo.br/pdf/reeusp/v46n2/a12v46n2.pdf. Acesso em 06 abr. 2016.

SILVA, Carla Marins e VARGENS, Octávio Muniz da Costa. Percepção de mulheres quanto a vulnerabilidade feminina para contrair DST/Aids. Rev.Esc. enferm. USP, 43(2):401-6, 2009.

Disponível em: http://www.scielo.br/pdf/reeusp/v43n2/a20v43n2.pdf. Acesso em: 23 de jul, 2016.

SILVA, Girlene Alves e REIS, Valesca Nunes dos. Construindo Caminhos de Conhecimentos em HIV/Aids: mulheres em cena. Physis Revista de Saúde Coletiva, Rio de Janeiro, 22 [ 4 ]: 1439-1458, 2012. Disponível em: http://www.scielo.br/pdf/physis/v22n4/a10v22n4.pdf. Acesso em 18 de agost de 2016.

SILVA, Silvia Fernandes Ribeiro da et. al. Aids no Brasil: uma epidemia em transformação. RBAC, vol. 42(3): 209-212, 2010. Disponível em: http://www.sbac.org.br/rbac/020/302.pdf. Acesso em: 21 fev. 2016. 
SOUZA, Maria da Consolação Pitanga de; SANTO, Antônio Carlos Gomes do Espírito e MOTTA, Sophia Karlla Almeida. Gênero, Vulnerabilidade das Mulheres ao HIV/ Aids e Ações de Prevenção em Bairro da Periferia de Teresina, Piauí, Brasil. Saúde Soc. São Paulo, v.17, n.2, p.58-68, $2008 . \quad$ Disponível em: http://www.scielo.br/pdf/sausoc/v17n2/07.pdf. Acesso em 19 de agost de 2016.

SOUSA, Marcela; SILVA, Michelly Dias; CARVALHO, Rachel de. Revisão integrativa: o que é e como fazer. Einstein, 2010 8(1 Pt 1):102-6. Disponível em: http://www.scielo.br/pdf/eins/v8n1/pt_1679-4508-eins-8-1-0102.pdf. Acesso em 04 abr, 2016.

SANTOS; Naila J. S. et. al. Contextos de vulnerabilidade para o HIV entre mulheres brasileiras. Cad. Saúde Pública, Rio de Janeiro, 25 Sup 2:S321-S333, 2009. Disponível em: http://www.scielosp.org/pdf/csp/v25s2/14.pdf. Acesso em 01 abr, 2016.

TAQUETTE, Stella R.. Interseccionalidade de Gênero, Classe e Raça e Vulnerabilidade de Adolescentes Negras às DST/aids. Saúde Sociedade, São Paulo, v.19, supl.2, p.51-62, 2010. Disponível em: http://www.scielo.br/pdf/sausoc/v19s2/06.pdf. Acesso em 27 jul. 2016.

Enviado: Setembro, 2019.

Aprovado: Fevereiro, 2020. 